\title{
An Optimal Power Flow Based Dispatch Model for Distributed Generation Embedded Network
}

\author{
Yufeng Lin, Student Member, IEEE, Jin Zhong, Member, and Math H.J. Bollen, Fellow, IEEE
}

\begin{abstract}
The installation of distributed generation (DG) introduces challenges to distribution systems operation. The distribution network operator needs to schedule DG outputs considering some constraints, such as DG characteristics, reactive power control mode of generators, automatic voltage regulation, compensator and power quality standard, etc. Based on an optimal power flow model, this paper proposes a dispatch model for DG embedded distribution systems. The model is proposed basing on energy prices, weather forecasting and load forecasting. The objective is to minimize the electricity supply cost of the distribution company. The proposed model is tested in the 33-buse system. The results show that DisCo's cost and losses of the distribution system can be reduced by enhancing system operation flexibility.
\end{abstract}

Index Terms-Distributed generation, dispatch model, optimal power flow

\section{NOMENCLATURE}

\section{A. Parameters}

$i$ : DG number.

$j, k$ : Bus number.

$\rho_{S}\left(P_{S}\right)$ : Price of electricity from power grid, $\$ / M W h$.

$\rho_{D G i}:$ Offer from $D G_{i}, \$ / M W h$.

$G_{j k}$ : Real part of admittance matrix element.

$B_{j k}$ : Imaginary part of admittance matrix element.

$\theta_{j k}$ : Phase angle difference between bus $j$ and bus $k$.

$\underline{P}_{D G i}$ : Lower boundary of $D G_{i}$ output.

$\bar{P}_{D G i}:$ Maximum output of $D G_{i}$.

$\eta_{w}: \quad$ Overall efficiency of wind turbine.

$\rho_{w}: \quad$ Air density, $m / s$.

$A$ : $\quad$ Wind turbine rotor area, $m^{3}$.

$C_{w}: \quad$ Optimal power coefficient of wind turbine.

$V: \quad$ Wind velocity, $\mathrm{m} / \mathrm{s}$

$\bar{P}_{D G i, W}$ : Rated active power of wind turbine, $W$.

$Q: \quad$ Flow rate, $\mathrm{m}^{3} / \mathrm{s}$.

$H$ : $\quad$ Effective head of hydro power plant, $m$.

$\eta_{h}$ : Overall efficiency of hydro power plant.

This work was supported by the HKU Seed Funding Program for Basic Research (Project code: 200811159092), HKU Strategic Research Theme and the University Development Funding (Initiative on Clean Energy \& Environment).

Y. Lin and J. Zhong are with the Department of Electrical \& Electronic Engineering, the University of Hong Kong, HKSAR (e-mails: yflin@eee.hku.hk, jzhong@eee.hku.hk).

M.H.J. Bollen is with EMC-on-Site, Luleå University of Technology, 97431 Skellefteå and with, STRI AB, 77180 Ludvika, Sweden (e-mail: math.bollen@stri.se) $\rho_{h}: \quad$ Water density, $\mathrm{kg} / \mathrm{m}^{3}$.

g: $\quad$ Acceleration due to gravity, $\mathrm{m} / \mathrm{s}$.

$\bar{P}_{D G i, H}$ : Rated active power of hydro power plant, $W$.

$a_{1}, a_{2}$ and $a_{3}$ : Coefficients related to the design of CHP.

$p$ : $\quad$ Steam pressure of CHP, ata.

$G$ : $\quad$ Steam flux, Tun/Hour.

$G_{l}$ : High pressure extraction of CHP, Tun/Hour.

$G_{2}$ : Low pressure extraction of CHP, Tun/Hour.

$\Delta H$ : Steam enthalpy drop in turbine low pressure stage, J/Tun.

$\eta_{g}: \quad$ Turbine low pressure stage efficiency.

$x_{s, D G i}$ : Synchronous reactance, $p u$.

$\bar{E}_{q, D G i}:$ Maximum internal voltage, $p u$.

$Q_{\min , D G i}$ : Region heating limit, MVar.

$S_{D G i:} \quad$ Rated capacity, $M V A$.

$r_{r}: \quad$ Rotor resistance, $p u$.

$x_{r}$ : $\quad$ Rotor reactance, $p u$.

$r_{s}: \quad$ Stator resistance, $p u$.

$x_{s}: \quad$ Stator reactance, $p u$.

$x_{m}$ : Excitation reactance, $p u$.

$S: \quad$ Induction generator slip.

$P F_{D G i}$ : Power factor of $D G_{i}$.

$\underline{V}$ : $\quad$ Lower voltage boundary on bus, $p u$.

$\bar{V}: \quad$ Upper voltage boundary on bus, $p u$.

$V_{S}$ : Lower boundary of substation secondary side voltage, pu.

$\bar{V}_{S}$ : Upper boundary of substation secondary side voltage, pu.

$V_{\text {set }}: \quad$ Set point of substation secondary side voltage, $p u$.

$Q_{C, j}^{\prime}$ : Reactive power of fixed capacitor on bus $j$ when the voltage is $1.0 \mathrm{pu}$, Mvar.

$\bar{Q}_{S V C, j}:$ Maximum reactive power of SVC on bus $j$ when the voltage is $1.0 \mathrm{pu}$, Mvar.

$\underline{Q}_{S V C, j}:$ Minimum reactive power of SVC on bus $j$ when the voltage is $1.0 \mathrm{pu}$, Mvar.

\section{B. Variables}

$P_{S}: \quad$ Active power from power grid, $M W$.

$P_{D G i}: \quad$ Active power from $D G_{i}, M W$.

$P_{G j}$ : Total DG active power on bus $j, M W$.

$P_{D j}$ : Total active power demand on bus $j, M W$.

$V_{j}$ : Voltages on bus $j, p u$.

$V_{k}$ : Voltages on bus $k, p u$.

$V_{D G i}$ : Terminal voltage of $D G_{i}, p u$.

$V_{S}$ : $\quad$ Substation secondary side voltage, $p u$. 
$Q_{C, j}: \quad$ Reactive power of fixed capacitor on bus $j$, Mvar.

$Q_{S V C, j}:$ Reactive power of SVC on bus $j$, Mvar.

\section{INTRODUCTION}

$\mathrm{D}$ UE to the increasing concerns on the global warming, and the exhaustion of fossil fuels, clean energy based distributed generation is recognized as one of the feasible approaches for sustainable development. It is expected that the penetration rate of DGs in power system will keep rising and the conventional power system will evolve from a centralized generating system to a more decentralized one. Moreover, DGs have potential advantages to reduce power delivery losses, postpone or shift transmission system investment, and increase system reliabilities.

In a DG embedded distribution system, distribution network operators (DNOs) dispatch DGs to maximize social welfare, while satisfy system operation constrains. Hereby, price signals, DG techniques, system operation guidelines, and power quality standards could affect the operation results.

Various DG techniques used currently have different power characteristics. Some renewable energy based DG are subject to the meteorologic conditions, such as wind speed, solar radiation, and flow rate, etc [1], [2]. The electrical outputs of combined-heat-and-powers (CHPs) depend on heat load [3]. Other DGs, such as steam turbine, gas turbine and combined cycle turbine, are highly controllable [1], [2]. DGs' abilities on adjusting reactive power are different. Synchronous machine, double-fed machine or self-commutated converter based DGs can adjust their reactive power outputs for terminal voltage regulation or power factor control. The DGs using induction machines or line-commutated converters are not able to adjust reactive output [1]-[6].

Operation guidelines for distribution system are different from one region to another. DGs are operated in fixed power factor mode or voltage control mode in different systems [7], [8]. In recent years, active management has been applied as an alternative approach to improve system efficiency. In active management, the set points of AVRs can be adjusted real time, and, in some cases, fixed capacitors are replaced by SVCs, which have variable admittance [11]-[13].

Voltage variation is an important issue for system operation. Though detailed definitions of voltage variation are diverse in different standards, voltage variation is commonly known as a phenomenon that unacceptable steady voltage deviation occurs on buses [14]-[16]. In traditional distribution system with few generator embedded, voltage magnitude normally droop gradually along feeder. This situation is no longer true due to the installation of DG, which can change system voltage profile.

In this context, economical operation in a DG embedded distribution system is a challenge for DNOs. Some voltage control strategies and dispatch models have been proposed for this issue. For example, Viawan and Karlsson introduce the methods to minimize system losses by coordinating on-load tap changers, capacitors, and switches in the DG embedded system [9-10]. A widespread communication based strategy is discussed to minimize a linear combination of distribution losses and voltage magnitude marginal [17]. A market model is proposed for distribution companies to coordinate wholesale market, load curtailment, distribution company (DisCo) owned DGs, and independent DGs [18]. The objective of the model is to minimize the total cost to procure the active power and reactive power.

In this paper, an optimal power flow (OPF) based dispatch model is proposed for the distribution system with DGs. The objective function is to minimize DisCo's cost. DG techniques, system operation guidelines, and voltage variation standards are described in the constraints.

The structure of this paper is as follows. Section II describes the models used in this paper. Section III and IV are the case studies and conclusions, respectively.

\section{MODEL DESCRIPTION}

\section{A. Dispatch procedure}

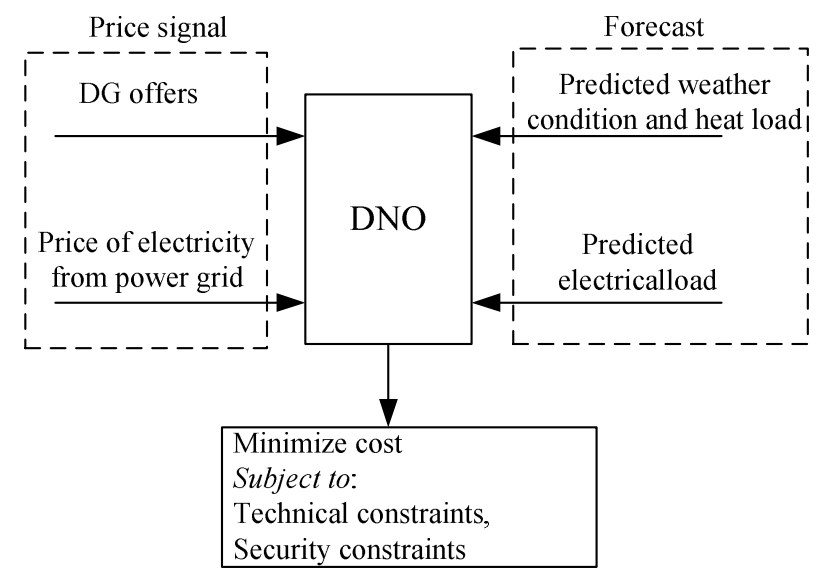

Fig. 1. Dispatch procedure for DG embedded distribution system

The proposed model is based on the assumption that DGs are independent and dispatchable. The dispatch procedure is shown in Fig.1. The DNO first receives offers from DGs. The weather conditions and heat loads are predicted to forecast the generation of renewable based DGs and CHPs for source-load matching. Based on this, the dispatch model is established. The objective of this model is to minimize the total cost of DisCo for energy supply, subjected to following constraints:

- Active power of renewable DGs: Maximum outputs of renewable DGs are subjected to generator capacities and weather conditions. On the other hand, in many countries, minimum outputs of renewable DGs are guaranteed in terms of laws, operation guidelines, or other terms from policy makers. In this paper, wind power generation and hydro power plant are considered as renewable DGs.

- Active power of CHP: The most commonly used CHP is steam turbine based CHP, which can be divided into two types, back-pressure CHP and condensing CHP. For the former one, all steam passes through the turbine and active power is determined only by heat demand [5]. While, condensing CHP can extract steam from the turbine for heat supply [5]. Its active power is adjustable [7]. 
- Active and reactive power characteristics (P-Q characteristics) of generators: $\mathrm{P}-\mathrm{Q}$ characteristics affect system voltage profile significantly. Therefore, detailed steady state generator models are used in this paper. The output of synchronous generator is subjected to its field heating, armature heating and end region heating. Induction generator outputs are subjected to armature heating and slip.

- Reactive power control of synchronous generator: At fixed power factor mode, the proportion between active power and reactive power is a constant. While in voltage control mode, generator terminal voltage is kept constant by adjusting generator reactive power.

- AVR control strategy: The set point of the substation secondary side voltage is constant in the conventional AVR, while flexible in active management mode.

- Compensator performance: The equivalent admittances of fixed capacitors are constant. While those of SVCs are adjustable.

\section{B. Objective function}

The objective function is to minimize DisCo's cost:

$$
\operatorname{MIN}\left[\left(P_{S} * \rho_{S}\left(P_{S}\right)+\sum P_{D G i} * \rho_{D G i}\right)\right]
$$

In this paper, the relationship between $\rho_{S}\left(P_{S}\right)$ and $P_{S}$ is described by a linear function.

$$
\rho_{S}\left(P_{S}\right)=a * P_{S}+b
$$

\section{Constraints}

The constraints are introduced as following:

- Power balance constraints:

$$
\begin{aligned}
& P_{G j}-P_{D j}=V_{j} \sum_{k=1}^{N} V_{k}\left(G_{j k} \cos \theta_{j k}+B_{j k} \sin \theta_{j k}\right) \\
& Q_{G j}-Q_{D j}=V_{j} \sum_{k=1}^{N} V_{k}\left(G_{j k} \sin \theta_{j k}-B_{j k} \cos \theta_{j k}\right)
\end{aligned}
$$

- $\quad$ Active power of renewable DG:

$$
\underline{P}_{D G i} \leq P_{D G i} \leq \bar{P}_{D G i}
$$

For wind power generation [5]:

$$
\bar{P}_{D G i}=\min \left[0.5 \eta_{w} \rho_{w} A C_{w} V^{3}, \bar{P}_{D G i, W}\right]
$$

For hydro power plant [5]:

$$
\bar{P}_{D G i}=\min \left[Q H \eta_{h} \rho_{h} g, \bar{P}_{D G i, H}\right]
$$

In this paper, it is assumed that $\underline{P}_{D G i}=0.5 \bar{P}_{D G i}$.

- $\quad$ Active power of CHP:

For back-pressure CHP [7]:

$$
P_{D G i}=\left(a_{1}-a_{2} p\right) G+a_{2}
$$

For condensing CHP [7]:

$$
\begin{aligned}
& P_{D G i} \leq P_{D G i} \leq \bar{P}_{D G i} \\
& P_{D G i, C H P}=\sum_{n=1}^{3} a_{n} G_{1}{ }^{n}-\frac{G_{2} \Delta H}{3600} \eta_{g} .
\end{aligned}
$$

- $\quad$ P-Q characteristics of DG:

For synchronous generator [20]:

$$
\left\{\begin{array}{c}
P_{D G i}^{2}+\left(Q_{D G i}+\frac{V_{D G i}}{x_{s, D G i}}\right)^{2} \leq\left[\frac{V_{D G i} * \bar{E}_{q, D G i}}{x_{s, D G i}}\right]^{2} \\
P_{D G i}^{2}+Q_{D G i}^{2} \leq S_{D G i}^{2} \\
Q_{D G i} \geq Q_{\min , D G i}
\end{array}\right.
$$

For induction generator [20]:

$$
\begin{aligned}
& \left\{\begin{array}{c}
P_{D G i}=\frac{-r_{e} V_{D G i}^{2}}{\sqrt{r_{e}^{2}+x_{e}^{2}}} \\
Q_{D G i}=\frac{x_{e}}{r_{e}} P_{D G i} \\
P_{D G i}^{2}+Q_{D G i}^{2} \leq S_{D G i}^{2}
\end{array}\right. \\
& \left\{\begin{array}{l}
r_{e}=\frac{r_{r} x_{m}^{2} S}{r_{r}^{2}+S^{2}\left(x_{r}+x_{m}\right)^{2}}+r_{S} \\
x_{e}=\frac{x_{m} r_{r}^{2}+x_{m} x_{r}\left(x_{m}+x_{r}\right) S^{2}}{r_{r}^{2}+S^{2}\left(x_{r}+x_{m}\right)^{2}}+x_{s}
\end{array}\right.
\end{aligned}
$$

- Reactive power control of synchronous generators:

Fixed power factor mode:

$P_{D G i} / \sqrt{P_{D G i}^{2}+Q_{D G i}^{2}}=P F_{D G i}$

Voltage control mode:

$\underline{V} \leq V_{D G i} \leq \bar{V}$

In this paper, $\underline{V}=0.93$ and $\bar{V}=1.07$.

- $\quad$ AVR control strategy:

If conventional AVR is used:

$V_{S}=V_{\text {set }}$

In this paper, $V_{\text {set }}=1.05 \mathrm{pu}$.

If active management is used in AVR:

$V_{S} \leq V_{S} \leq \bar{V}_{S}$

In this paper, $V_{S}=1.0$ and $\bar{V}_{S}=1.07$.

- $\quad$ Bus voltage variation boundaries

$\underline{V} \leq V_{j} \leq \bar{V}$

- Compensator performance:

For fixed capacitor:

$Q_{C, j}=V_{j}^{2} * Q_{C, j}^{\prime}$

For SVC:

$V_{j}^{2} * \underline{Q}_{S V C, j} \leq Q_{S V C, j} \leq V_{j}^{2} * \bar{Q}_{S V C, j}$

\section{CASE StUdy}

The test system shown in Fig. 2 is a $10 \mathrm{kV}$ system with a substation, three DGs, and two compensators. The system data is given in Appendix (Table VI). DG types and capacities are shown in Table I. DG parameters are given in Appendix (Table VII). DG offers and electricity price of power grid are in Table II. The offer of condensing CHP is higher than that of back-pressure CHP.

The scenarios are in Appendix (Table VIII). They created are to investigate the sensitivities of DisCo's cost to different technique options. In case $\mathrm{A}$, all DGs are synchronous machines; back-pressure $\mathrm{CHP}$ and condensing $\mathrm{CHP}$ are applied in A1 and A2, respectively. In case B, DG1 and DG2 are induction machines and DG3 is a synchronous machine. 
DG3 uses back-pressure CHP in B1, while condensing CHP in B2. In case $\mathrm{C}$, all DGs operate in fixed power factor mode. In case $\mathrm{D}$, active management is used in AVR; and SVC is used in $\mathrm{D} 2$.

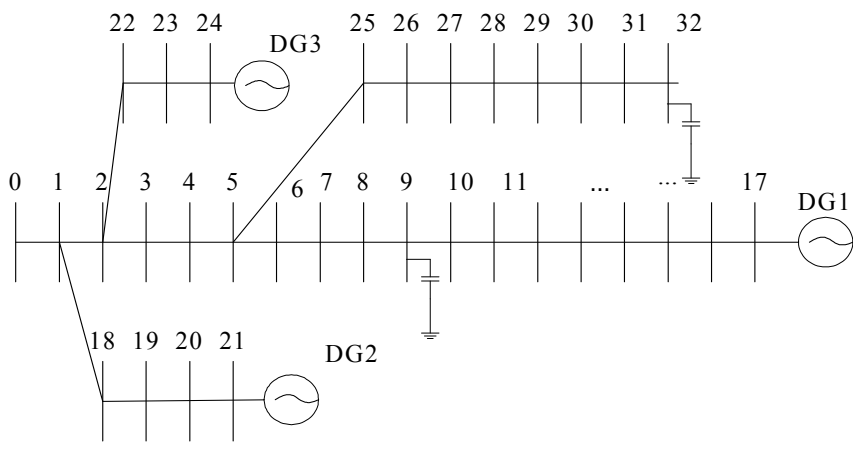

Fig. 2. Test system

TABLE I

DG TYPES AND CAPACITIES

\begin{tabular}{|l|c|c|c|}
\hline & Bus & Type & Capacity(MVA) \\
\hline DG1 & 17 & Hydro power plant & 0.75 \\
\hline DG2 & 21 & Wind power generation & 0.6 \\
\hline DG3 & 24 & CHP & 0.8 \\
\hline
\end{tabular}

TABLE II

DG OFFERS AND ELECTRICITY PRICE FROM POWER GRID

\begin{tabular}{|c|c|}
\hline DG1 & $23 \$ / \mathrm{MWh}$ \\
\hline DG2 & $75 \$ / \mathrm{MWh}$ \\
\hline DG3 & $26 \$ / \mathrm{MWh}$ for Back-pressure $\mathrm{CHP} ; 40 \$ / \mathrm{MWh}$ for Condensing CHP \\
\hline Power Grid & $\rho_{S}\left(P_{S}\right)=3 P_{S}+23(\$ / \mathrm{MWh})$ \\
\hline
\end{tabular}

The expected DG biddable generation capacities according to predicted wind speed, predicted flow rate and predicted heat demand are shown in Table III.

TABLE III

EXPECTED BIDDABLE GENERATION CAPACITIES OF DGs

\begin{tabular}{|c|c|}
\hline DG1 & {$[0.2,0.4] \mathrm{MW}$} \\
\hline DG2 & {$[0.15,0.3] \mathrm{MW}$} \\
\hline \multirow{2}{*}{ DG3 } & $\begin{array}{c}0.365 \mathrm{MW} \text { for back-pressure CHP } \\
{[0.269,0.8] \mathrm{MW} \text { for condensing CHP }}\end{array}$ \\
\hline
\end{tabular}

Table IV shows dispatch result for each scenario according to the demand given in Table VI. Table V are the dispatch results in cases that demand increases by 20 percent.

TABLE IV

DisPATCH RESUlt FOR THE DEMAND IN TABLE VI

\begin{tabular}{|l|c|c|c|c|c|c|}
\hline & & \multicolumn{4}{|c|}{ Active power of DGs and power grid (MW) } & \\
\hline & Total cost (\$) & DG1 & DG2 & DG3 & Power grid & $\begin{array}{c}\text { Distribution } \\
\text { loss (\%) }\end{array}$ \\
\hline A1 & 123.4493 & 0.4000 & 0.1500 & 0.3654 & 2.9387 & 6.3206 \\
\hline A2 & 128.2513 & 0.4000 & 0.1500 & 0.6358 & 2.6591 & 6.0645 \\
\hline B1 & 124.1925 & 0.4000 & 0.1500 & 0.3654 & 2.9570 & 6.8245 \\
\hline B2 & 128.9655 & 0.4000 & 0.1500 & 0.6482 & 2.6647 & 6.5611 \\
\hline C1 & 129.0413 & 0.4000 & 0.1500 & 0.5681 & 2.7482 & 6.6572 \\
\hline C2 & 129.2035 & 0.4000 & 0.1500 & 0.5992 & 2.7207 & 6.7578 \\
\hline
\end{tabular}

\begin{tabular}{|l|l|l|l|l|l|l|}
\hline $\mathrm{C} 3$ & 129.4670 & 0.4000 & 0.1500 & 0.6325 & 2.6935 & 6.9253 \\
\hline $\mathrm{C} 4$ & 130.1263 & 0.4000 & 0.1500 & 0.6706 & 2.6714 & 7.3662 \\
\hline $\mathrm{C} 5$ & 131.1616 & 0.3952 & 0.1500 & 0.5711 & 2.8015 & 8.0764 \\
\hline $\mathrm{D} 1$ & 128.0273 & 0.4000 & 0.1500 & 0.6447 & 2.6441 & 5.8988 \\
\hline $\mathrm{D} 2$ & 123.5511 & 0.4000 & 0.1500 & 0.5496 & 2.6268 & 2.7975 \\
\hline
\end{tabular}

TABLE V

DisPatch Result IF THE DEMAND IN TABLE VI INCREASES 20 PERCENT

\begin{tabular}{|c|c|c|c|c|c|c|}
\hline & & Active $\mathrm{p}$ & wer of D & Is and $p$ & ver grid (MW) & \\
\hline & $\begin{array}{c}\text { Total cost } \\
(\$)\end{array}$ & DG1 & DG2 & DG3 & Power Grid & $\begin{array}{c}\text { Distribution } \\
\text { loss }(\%))\end{array}$ \\
\hline $\mathrm{A} 1$ & 156.8114 & 0.4000 & 0.1500 & 0.3654 & 3.7153 & 6.4522 \\
\hline $\mathrm{A} 2$ & 159.4023 & 0.4000 & 0.1500 & 0.7902 & 3.2713 & 6.0115 \\
\hline B1 & 157.3402 & 0.4000 & 0.1500 & 0.3654 & 3.7269 & 6.7204 \\
\hline $\mathrm{B} 2$ & 159.9486 & 0.4000 & 0.1500 & 0.7929 & 3.2816 & 6.3099 \\
\hline $\mathrm{C} 1$ & 160.9470 & 0.4000 & 0.1500 & 0.6799 & 3.4097 & 6.6574 \\
\hline $\mathrm{C} 2$ & 160.7992 & 0.4000 & 0.1500 & 0.7201 & 3.3692 & 6.6501 \\
\hline $\mathrm{C} 3$ & 160.7170 & 0.4000 & 0.1500 & 0.7637 & 3.3268 & 6.6781 \\
\hline $\mathrm{C} 4$ & 160.9865 & 0.4000 & 0.1500 & 0.8000 & 3.2992 & 6.8786 \\
\hline $\mathrm{C} 5$ & 161.9093 & 0.4000 & 0.1500 & 0.7637 & 3.3545 & 7.3148 \\
\hline D1 & 159.3878 & 0.4000 & 0.1500 & 0.7917 & 3.2696 & 6.0059 \\
\hline $\mathrm{D} 2$ & 155.0934 & 0.4000 & 0.1500 & 0.7793 & 3.1799 & 3.6589 \\
\hline
\end{tabular}

\section{A. Discussions}

Based on the results in Table III and Table V, the following can be found

- $\quad$ Using back-pressure CHP can reduce the total cost. In Table IV and Table V, the total costs in A1 and B1 are lower than those in $\mathrm{A} 2$ and $\mathrm{B} 2$, respectively. This is because back-pressure CHP has higher coal utilization rate; thus, can provide lower offer.

- Compared with back-pressure CHP, condensing CHP can improve distribution efficiency. This can be observed in Case A and Case B where the distribution losses in A1 and $\mathrm{B} 1$ are higher than those in $\mathrm{A} 2$ and $\mathrm{B} 2$, respectively. This is due to the adjustability of CHP active power. Back-pressure CHP can not adjust active power in a given heat load, while condensing CHP can adjust both active power and reactive power.

- Synchronous generator has potential advantage to improve distribution efficiency rather than induction generator. However, this potential advantage is achieved only if appropriate reactive power control scheme is used. The distribution losses in $\mathrm{A} 1$ and $\mathrm{A} 2$ are lower than $\mathrm{B} 1$ and $\mathrm{B} 2$, respectively. This fact illustrates that distribution efficiency can be improved if induction generator is replaced by synchronous generator with voltage control mode. While fixed power factor mode is not able to reduce distribution loss. For example, distribution losses of C1-C5 are higher than loss of B2.

- Distribution loss varies with power factor set point and load level. Take Case C for example, in Table IV, distribution loss increases scenario by scenario; while in Table V, C2 has a distribution loss lower than losses in $\mathrm{C} 1, \mathrm{C} 3, \mathrm{C} 4$ and $\mathrm{C} 5$.

- The enhancement of system flexibility can reduce total cost and distribution loss. This can be investigated from Case D. In D1, substation secondary side voltage is 
variable and capacitors are fixed; it has lower cost and distribution loss than those in A2, B2 and Case C, whose substation secondary side voltages and capacitors are fixed. In D2, SVC is employed to replace fixed capacitors; the cost and distribution loss in D2 are even lower than those in D1.

\section{CONCLUSION}

This paper proposed an OPF based dispatch model for distribution systems with independent DGs. This model aims to allocate DG outputs according to electricity price signals, load forecasting, and weather forecasting, while take into account operation and security constraints.

Cases are studied to verify the impact of technical factors, such as steam turbine types, generator types, reactive power control, AVR control, and compensator, on DisCo's cost and distribution losses. Back-pressure CHP can reduce DisCo's cost, however, it results in higher distribution losses due to lack of active power controllability. One feasible solution to reduce cost as well as enhance distribution efficiency is to improve system flexibility, such as using synchronous generator with voltage control mode, managing AVR actively, and installing SVC.

\section{APPENDIX}

TABLE VI

PARAMETERS OF 33-BUS DISTRIBUTION SYSTEM

\begin{tabular}{|c|c|c|c|c|c|}
\hline \multicolumn{2}{|c|}{ Branch } & & & \multicolumn{2}{|c|}{ Load on sending end } \\
\hline Sending end & Receiving end & $\mathrm{r}(\mathrm{pu})$ & $\mathrm{x}(\mathrm{pu})$ & $\mathrm{P}(\mathrm{MW})$ & Q(Mvar) \\
\hline 1 & 2 & 0.493 & 0.2511 & 0.1 & 0.06 \\
\hline 1 & 18 & 0.164 & 0.1563 & 0.09 & 0.04 \\
\hline 1 & 0 & 0.0992 & 0.047 & 0.12 & 0.08 \\
\hline 2 & 3 & 0.366 & 0.1864 & 0.06 & 0.03 \\
\hline 2 & 22 & 0.4512 & 0.3083 & 0.06 & 0.02 \\
\hline 3 & 4 & 0.3881 & 0.1941 & 0.2 & 0.1 \\
\hline 4 & 5 & 0.819 & 0.707 & 0.2 & 0.1 \\
\hline 5 & 6 & 0.1872 & 0.6188 & 0.06 & 0.02 \\
\hline 5 & 25 & 0.203 & 0.1034 & 0.06 & 0.02 \\
\hline 6 & 7 & 0.7114 & 0.2351 & 0.045 & 0.03 \\
\hline 7 & 8 & 1.03 & 0.74 & 0.06 & 0.035 \\
\hline 8 & 9 & 1.044 & 0.74 & 0.06 & 0.035 \\
\hline 9 & 10 & 0.1966 & 0.065 & 0.12 & 0.08 \\
\hline 10 & 11 & 0.3744 & 0.1238 & 0.06 & 0.01 \\
\hline 11 & 12 & 1.468 & 1.155 & 0.06 & 0.02 \\
\hline 12 & 13 & 0.5416 & 0.7129 & 0.06 & 0.02 \\
\hline 13 & 14 & 0.591 & 0.526 & 0.09 & 0.04 \\
\hline 14 & 15 & 0.7463 & 0.545 & 0.09 & 0.04 \\
\hline 15 & 16 & 1.289 & 1.721 & 0.09 & 0.04 \\
\hline 16 & 17 & 0.732 & 0.574 & 0.09 & 0.04 \\
\hline 18 & 19 & 1.5042 & 1.3554 & 0.09 & 0.04 \\
\hline 19 & 20 & 0.4095 & 0.4784 & 0.09 & 0.05 \\
\hline 20 & 21 & 0.7089 & 0.9373 & 0.42 & 0.2 \\
\hline 22 & 23 & 0.898 & 0.7091 & 0.42 & 0.2 \\
\hline 23 & 24 & 0.896 & 0.7011 & 0.06 & 0.025 \\
\hline 25 & 26 & 0.2842 & 0.1447 & 0.06 & 0.025 \\
\hline 26 & 27 & 1.059 & 0.9337 & 0.06 & 0.02 \\
\hline 27 & 28 & 0.8042 & 0.7006 & 0.12 & 0.07 \\
\hline 28 & 29 & 0.5075 & 0.2585 & 0.2 & 0.6 \\
\hline 29 & 30 & 0.9744 & 0.963 & 0.06 & 0.04 \\
\hline 30 & 31 & 0.3105 & 0.3619 & 0.21 & 0.1 \\
\hline 31 & 32 & 0.341 & 0.5302 & 0.06 & 0.04 \\
\hline \multicolumn{2}{|c|}{ Fixed capacitor on bus9 } & \multicolumn{4}{|c|}{$2.25 \mathrm{Mvar}$} \\
\hline \multicolumn{2}{|c|}{ Fixed capacitor on bus32 } & \multicolumn{4}{|c|}{$0.4 \mathrm{Mvar}$} \\
\hline
\end{tabular}

\begin{tabular}{|c|c|}
\hline SVC on bus 9 & {$[-4.5 \mathrm{Mvar}, 4.5 \mathrm{Mvar}]$} \\
\hline SVC on bus32 & {$[-0.8 \mathrm{Mvar}, 0.8 \mathrm{Mvar}]$} \\
\hline Base Voltage & $10 \mathrm{kV}$ \\
\hline Base Capacity & $100 \mathrm{MA}$ \\
\hline
\end{tabular}

TABLE VII

PARAMETERS OF DGS

\begin{tabular}{|c|c|c|c|c|}
\hline \multicolumn{2}{|c|}{} & DG1 & DG2 & DG3 \\
\hline \multicolumn{2}{|c|}{ Base Voltage(kV) } & 10 & 10 & 10 \\
\hline \multicolumn{2}{|c|}{ Base Capacity(MVA) } & 0.75 & 0.6 & 0.8 \\
\hline \multirow{3}{*}{ Synchronous generator } & $\mathrm{x}_{\mathrm{s}}(\mathrm{pu})$ & \multicolumn{3}{|c|}{1.536} \\
\cline { 2 - 5 } & $\overline{E_{q}}(p u)$ & \multicolumn{2}{|c|}{2.231} \\
\hline \multirow{4}{*}{$\begin{array}{c}\text { Induction } \\
\text { generator }\end{array}$} & $\mathrm{r}_{\mathrm{s}}(\mathrm{pu})$ & 0.0241 & - \\
\cline { 2 - 5 } & $\mathrm{x}_{\mathrm{s}}(\mathrm{pu})$ & 0.139 & - \\
\cline { 2 - 5 } & $\mathrm{r}_{\mathrm{r}}(\mathrm{pu})$ & 0.22 & - \\
\cline { 2 - 5 } & $\mathrm{x}_{\mathrm{r}}(\mathrm{pu})$ & 0.351 & - \\
\cline { 2 - 5 } & $\mathrm{x}_{\mathrm{m}}(\mathrm{pu})$ & 9.1 & - \\
\hline
\end{tabular}

\section{REFERENCES}

[1] Jörss, W., Jørgensen, B.H., Löffler, P., Morthorst, P.E., Uyterlinde, M., Sambeek, E. van, Wehnert, T, Decentralized power generation in the liberalized EU energy markets. Berlin: Springer-Verlag, 2003.

[2] Nick Jenkins, Ron Allan, Peter Crossley, Daniel Kirschen, Goran Strbac. Embedded generation. London: The institution of electrical engineers, 2000.

[3] Ni Jingfeng, "The Study and Software Implementation for the HeatLoad-based CHP Units," Master dissertation, Department of thermal engineering, North China Electric Power University; 2004.

[4] Refoufi, L. Al Zahawi, B.A.T., "Analysis and modeling of the steady state behavior of the static Kramer induction generator," IEEE Trans. Energy Conversion, vol. 14, no. 3, pp. 333-339, May 1999.

[5] Wasynczuk, O, "Modeling and Dynamic Performance of a LineCommutated Photovoltaic Inverter System," IEEE Power Engineering Review, vol.9, no. 9, pp. 35-36, 1989.

[6] Wasynczuk, O., Anwah, N. A, "Modeling and dynamic performance of a self-commutated photovoltaic inverter system," IEEE Power Engineering Review, vol.9, no. 9, pp. 33-34, 1989.

[7] Vovos, P.N., Kiprakis, A.E., Wallace, A.R., Harrison, G.P., "Centralized and distributed voltage control: impact on distributed generation penetration," IEEE Trans. Power System, vol. 22, no. 1, pp. 476-483, 2009.

[8] China State Grid, Management Guide for Power System Voltage and Reactive Power. Beijing: China State Grid, Jan. 2005.

[9] Viawan, F.A., Karlsson, D, "Voltage and reactive power control in systems with synchronous machine-based distributed generation," IEEE Trans. Power Delivery, vol. 23, no. 2, pp. 1079-1087, 2008.

[10] Viawan, F.A., Karlsson, D., "Combined local and remote voltage and reactive power control in the presence of induction machine distributed generation," IEEE Trans. Power System, vol. 22, no. 4, pp. 2003-2012, 2007.

[11] Liew, S.N., Strbac, G., "Maximising penetration of wind generation in existing distribution networks," Generation, Transmission and Distribution, IEE Proceedings, vol. 149, no.3, pp. 256-262, 2002.

[12] Shafiu, A., Bopp, T., Chilvers, I., Strbac, G, "Active management and protection of distribution networks with distributed generation," in 2004 Power Engineering Society General Meeting, pp.1098-1103.

[13] Wang, D.T.-C., Ochoa, L.F., Harrison, G.P., "Assessing the economic impact of distributed generation on voltage regulation in distribution networks," in 2008 Universities Power Engineering Conference, pp.1-6. 
TABLE VIII

SCENARIOS FOR CASE STUDY

\begin{tabular}{|c|c|c|c|c|c|c|c|c|c|c|}
\hline \multirow[b]{2}{*}{ Case } & \multirow[b]{2}{*}{ Scenario } & \multicolumn{2}{|r|}{ DG1 } & \multicolumn{2}{|r|}{ DG2 } & \multicolumn{3}{|c|}{ DG3 } & \multirow[b]{2}{*}{$\begin{array}{c}\text { AVR@ } \\
\text { Constraints }\end{array}$} & \multirow[b]{2}{*}{$\begin{array}{l}\text { Compensator } \\
\text { @Constraints }\end{array}$} \\
\hline & & $\begin{array}{l}\text { Gen Type@ } \\
\text { Constraints }\end{array}$ & $\begin{array}{c}\text { Reactive power } \\
\text { control@ } \\
\text { Constraints }\end{array}$ & $\begin{array}{l}\text { Gen Type@ } \\
\text { Constraints }\end{array}$ & $\begin{array}{c}\text { Reactive power } \\
\text { control@ } \\
\text { Constraints }\end{array}$ & $\begin{array}{l}\text { Gen Type@ } \\
\text { Constraints }\end{array}$ & $\begin{array}{c}\text { Reactive power } \\
\text { control@ } \\
\text { Constraints }\end{array}$ & $\begin{array}{c}\text { CHP } \\
\text { Technique@ } \\
\text { Constraints }\end{array}$ & & \\
\hline \multirow{2}{*}{ A } & $\mathrm{A} 1$ & Syn.@(8) & VC@(11) & Syn.@(8) & VC@(11) & Syn.@(8) & VC@(11) & BP@(6) & FX@(12) & FC@(15) \\
\hline & $\mathrm{A} 2$ & Syn.@(9) & VC@(11) & Syn.@(8) & VC@(11) & Syn.@(8) & VC@(11) & CO@(7) & FX@(12) & FC@(15) \\
\hline \multirow{2}{*}{ B } & B1 & Ind.@(9) & - & Ind.@(9) & - & Syn.@(8) & VC@(11) & BP@(6) & FX@(12) & FC@(15) \\
\hline & $\mathrm{B} 2$ & Ind.@(9) & - & Ind.@(9) & - & Syn.@(8) & VC@(11) & $\mathrm{CO} @(7)$ & FX@(12) & FC@(15) \\
\hline \multirow{5}{*}{$\mathrm{C}$} & $\mathrm{C} 1$ & Syn.@(8) & PF@(10)@0.85Lag & Syn.@(8) & PF@(10)@0.85Lag & Syn.@(8) & PF@(10)@0.85Lag & $\mathrm{CO} @(7)$ & FX@(12) & FC@(15) \\
\hline & $\mathrm{C} 2$ & Syn.@(8) & PF@(10)@0.90Lag & Syn.@(8) & PF@(10)@0.90Lag & Syn.@(8) & PF@(10)@0.90Lag & $\mathrm{CO} @(7)$ & FX@(12) & FC@(15) \\
\hline & $\mathrm{C} 3$ & Syn.@(8) & PF@(10)@0.95Lag & Syn.@(8) & PF@(10)@0.95Lag & Syn.@(8) & PF@(10)@0.95Lag & $\mathrm{CO} @(7)$ & FX@(12) & FC@(15) \\
\hline & $\mathrm{C} 4$ & Syn.@(8) & PF@(10)@1.0 & Syn.@(8) & PF@(10)@1.0 & Syn.@(8) & PF@(10)@1.0 & $\mathrm{CO} @(7)$ & FX@(12) & FC@(15) \\
\hline & $\mathrm{C} 5$ & Syn.@(8) & PF@(10)@0.95Lead & Syn.@(8) & PF@(10)@0.95Lead & Syn.@(8) & PF@(10)@0.95Lead & $\mathrm{CO} @(7)$ & FX@(12) & FC@(15) \\
\hline \multirow{2}{*}{$\mathrm{D}$} & D1 & Syn.@(8) & VC@(11) & Syn.@(8) & vC@(11) & Syn.@(8) & VC@(11) & $\mathrm{CO} @(7)$ & AM@(13) & FC@(15) \\
\hline & D2 & Syn.@(8) & VC@(11) & Syn.@(8) & $\mathrm{VC} @(11)$ & Syn.@(8) & VC@(11) & CO@(7) & AM@(13) & SVC@(16) \\
\hline
\end{tabular}

[14] Power Quality application Guide, Voltage Disturbances, EN 50160, IEE, July 2004.

[15] IEEE recommended Practice for Monitoring Electric Power Quality, IEEE Standard 1159-1995, 1995.

[16] Power Quality Acceptable Deviation of Voltage for Supplying Power, Chinese Standard GB/T 12325-2003, 2003.

[17] Senjyu, T., Miyazato, Y., Yona, A., Urasaki, N., Funabashi, T., "Optimal distribution voltage control and coordination with distributed generation," IEEE Trans. Power Delivery, vol. 23, no. 2, pp. 1236-1242, 2008.

[18] Palma-Behnke, R., A, J.L.C., Vargas, L.S., Jofre, A, “A distribution company energy acquisition market model with integration of distributed generation and load curtailment options," IEEE Trans. Power System, vol. 20, no. 4, pp. 1718-1727, 2005.

[19] National Code for Renewable Energy, Chinese Public law, 2005.

[20] A. E. Fitzgerald, Charles Kingsley, Jr, Stephen D. Umans, Electric machinery. Beijing: Tsinghua University Press, 2003.

\section{BIOGRAPHIES}

Yufeng Lin (S'08) was born in Fujian, China, in March 1982. He received the BS degree from North China Electric Power University, China in 2003 and MS degree from Zhejiang University, China in 2006. He is now a PhD student in the Department of Electrical and Electronic Engineering, the University of Hong Kong. His main fields of interest are renewable energy and smart grid.

Jin Zhong ( $\left.\mathrm{S}^{\prime} 00, \mathrm{M}^{\prime} 05\right)$ received the B. Sc. (Eng.) degree from Tsinghua University, Beijing, China, in 1995 and the M. Sc. (Eng.) degree from the Electric Power Research Institute, Beijing, in 1998, and the Ph.D degree from Chalmers University of Technology, Gothenburg, Sweden, in 2003. She is an Assistant Professor in the Department of Electrical and Electronic Engineering at the University of Hong Kong.

Math Bollen (M'93-SM'96-F'05) received the M.Sc. and Ph.D. degrees from Eindhoven University of Technology, Eindhoven, The Netherlands, in 1985 and 1989, respectively. Currently, he is manager power quality and EMC at STRI AB, Ludvika, Sweden and guest professor at Luleå University of Technology, Skellefteå, Sweden. Before joining STRI in 2003, he was research associate at Eindhoven University of Technology, lecturer at the University of Manchester Institute of Science and Technology (UMIST), Manchester, U.K., and professor in electric power systems at Chalmers University of Technology, Gothenburg, Sweden. His current research interests include power quality, reliability, and integration of distributed generation and wind power in the grid. He has published more than 100 papers including a number of fundamental papers on voltage dip analysis and two textbooks on power quality, "understanding power quality problems" and "signal processing of power quality disturbances". 